\section{Altered Serotonin Synthesis in the Dentatothalamocortical Pathway in Autistic Boys}

Diane C. Chugani, PhD, ${ }^{*} \dagger$ Otto Muzik, PhD, $\dagger$ Robert Rothermel, PhD, $\$$ Michael Behen, BA, $\$$ Pulak Chakraborty, PhD, $\uparrow$ Thomas Mangner, $\mathrm{PhD}, \dagger$ Ednéa A. da Silva, MD, ${ }^{*}$ and Harry T. Chugani, MD* $\$$

Based on reports of increased platelet serotonin in 30 to $50 \%$ of autistic subjects, abnormal serotonergic neurotransmission may be important in the pathogenesis of autism. However, serotonin metabolite measurements in cerebrospinal fluid of autistic subjects have failed to demonstrate consistent abnormalities. Using $\alpha-\left[{ }^{11} \mathrm{C}\right]$ methyl-L-tryptophan as a tracer for serotonin synthesis with positron emission tomography, we now report unilateral alterations of serotonin synthesis in the dentatothalamocortical pathway in autistic boys. Asymmetries of serotonin synthesis were found in frontal cortex, thalamus, and dentate nucleus of the cerebellum in all 7 boys, but not in the 1 autistic girl studied. Decreased serotonin synthesis was found in the left frontal cortex and thalamus in 5 of the 7 boys and in the right frontal cortex and thalamus in the 2 remaining autistic boys. In all 7 cases, elevated serotonin synthesis in the contralateral dentate nucleus was observed. Statistically significant differences between autistic boys and their nonautistic siblings $(n=5)$ were obtained when comparing asymmetry indices for frontal cortex, thalamus, and dentate nucleus combined as well as individually for frontal cortex and thalamus. These serotonergic abnormalities in a brain pathway, important for language production and sensory integration, may represent one mechanism underlying the pathophysiology of autism.

Chugani DC, Muzik O, Rothermel R, Behen M, Chakraborty P, Mangner T, da Silva EA, Chugani HT. Altered serotonin synthesis in the dentatothalamocortical pathway in autistic boys. Ann Neurol 1997;42:666-669

Autistic disorder is estimated to occur in 1 of 2,000 live births, and is four times more common in boys than girls [1]. Autism is characterized by disturbances of social interaction, language, stereotypic motor behaviors, and an unreasonable need for sameness. De-

From the Departments of *Pediarrics, †Radiology, $\neq$ Neurology, and §Psychiatry, Children's Hospital of Michigan, Wayne State University School of Medicine, Detroit, MI.

Received Mar 26, 1997, and in revised form Apr 25. Accepred for publication Apr 25, 1997.

Address correspondence to Dr Diane Chugani, Children's Hospital of Michigan PET Center, 3901 Beaubien Blvd, Detroit, MI 48201. spite evidence suggesting that autism is an inherited disorder (reviewed in Reference 2), the cause of infantile autism has remained elusive. In 1961, Schain and Freedman [3] reported increased platelet serotonin in approximately one-third of autistic patients. Although this finding has been replicated by other investigators (reviewed in Reference 4), there have been no suitable noninvasive methods to measure human brain serotonin metabolism in vivo. Measurements of the serotonin metabolite 5-hydroxyindole acetic acid (5-HIAA) in cerebrospinal fluid (CSF) of autistic individuals have failed to show consistent abnormalities (for reviews, see References 4 and 5).

Recently, $\alpha-\left[{ }^{11} \mathrm{C}\right]$ methyl-L-tryptophan ( $\left.\left[{ }^{11} \mathrm{C}\right] \mathrm{AMT}\right)$ has been developed as a tracer for measuring serotonin synthesis, using positron emission tomography (PET) in animals [6] and humans [7, 8]. Because PET allows the measurement of regional changes in brain serotonin synthesis, $\left[{ }^{11} \mathrm{C}\right] \mathrm{AMT}$ PET is an ideal method to study alterations of serotonin metabolism in the brains of auristic subjects. In the present study, we tested the hypothesis that regional brain serotonin synthesis is altered in autistic children compared with their nonautistic siblings.

\section{Subjects and Methods}

Eight autistic children ( 7 boys, 1 girl; ages, 4.1-11.1 years; mean age, 6.6 years) and 5 of their siblings ( 4 boys, 1 girl; ages, 8.2-14.4 years; mean age, 9.9 years) were recruited from clinics at the Children's Hospital of Michigan. All children were given a battery of neuropsychological tests to assess the diagnosis of autism and to document behavioral characteristics (Table 1). Studies were performed in compliance with regulations of Wayne State University Human Investigation and Radiation Drug Research Committees, and informed consent of parent or guardian was obtained before all studies. In addition, the assent of the siblings was obtained.

Subjects were fasted for 6 hours before the PET procedure, to obtain stable plasma tryptophan levels during the course of the study. Plasma tryptophan, heart rate, blood pressure, pulse oximetry, and blood gases were measured periodically during the study. Children unable to cooperate for the scan were sedated with Nembutal $(5 \mathrm{mg} / \mathrm{kg}$ IV) or midazolam $(0.2-0.4 \mathrm{mg} / \mathrm{kg}$ IV). All autistic children and 3 of the 5 siblings required sedation. Prior studies performed in our laboratory on 5 adults each scanned twice (once without and once with sedation using midazolam) have found differences of less than $10 \%$ between the two testing conditions (in preparation); these differences are within the accepted test/retest range for PET tracers [9].

[ $\left.{ }^{11} \mathrm{C}\right] \mathrm{AMT}$ was produced by using the method described by Chakraborty and colleagues $[10] .\left[{ }^{11} \mathrm{C}\right] \mathrm{AMT}(0.1 \mathrm{mCi} /$ $\mathrm{kg}$ ) was injected intravenously as a slow bolus over $2 \mathrm{~min}$ utes. Thirty minutes after tracer injection, a static 20 -minute emission scan of the brain was acquired in three-dimensional mode. PET studies were performed using the Siemens EXACT/HR whole-body positron tomograph (Knoxville, 


\begin{tabular}{|c|c|c|c|c|c|c|c|c|c|}
\hline \multirow[b]{2}{*}{ Subject No. } & \multirow[b]{2}{*}{ Age $(y r)$} & \multirow[b]{2}{*}{ Sex } & \multicolumn{5}{|c|}{ GARS } & \multirow[b]{2}{*}{ CARS } & \multirow[b]{2}{*}{$\mathrm{OAB}^{\mathrm{a}} / \mathrm{FSIQ}^{\mathrm{b}}$} \\
\hline & & & SB & Com & SI & Dev & TOT & & \\
\hline \multicolumn{10}{|c|}{ Autistic group } \\
\hline 1 & 3.5 & $\mathrm{M}$ & 10 & 11 & 9 & 6 & 93 & 41.5 & $19^{\mathrm{a}}$ \\
\hline 2 & 4.1 & M & 11 & 13 & 12 & 9 & 108 & 41.0 & $23^{a}$ \\
\hline 3 & 4.1 & $F$ & 13 & 14 & 13 & 12 & 120 & 39.5 & $24^{a}$ \\
\hline 4 & 5.0 & M & 14 & 13 & 8 & 10 & 108 & 34.5 & $23^{a}$ \\
\hline 5 & 5.1 & M & 11 & 16 & 11 & 13 & 117 & 41.5 & $24^{a}$ \\
\hline 6 & 6.8 & M & 12 & 12 & 14 & 12 & 113 & 41.0 & $21^{a}$ \\
\hline 7 & 9.5 & M & 16 & 15 & 13 & 11 & 125 & ND & $29^{a}$ \\
\hline 8 & 11.0 & M & 11 & 15 & 12 & 11 & 115 & 39.0 & $16^{a}$ \\
\hline Mean & 6.1 & & & & & & 112 & 39.7 & $22^{\mathrm{a}}$ \\
\hline \multicolumn{10}{|c|}{ Sibling group } \\
\hline 9 & 8.2 & $\mathrm{M}$ & 4 & 1 & 3 & 0 & 47 & 20.5 & $109^{b}$ \\
\hline 10 & 8.6 & $\mathrm{M}$ & 2 & 3 & 2 & 1 & 47 & 16.5 & $130^{\mathrm{b}}$ \\
\hline 11 & 8.9 & $\mathrm{~F}$ & 1 & 1 & 2 & 1 & 42 & 17.0 & $122^{b}$ \\
\hline 12 & 9.4 & M & 5 & 1 & 1 & 1 & 45 & ND & $\mathrm{ND}^{\mathrm{b}}$ \\
\hline 13 & 14.4 & $\mathrm{M}$ & 1 & 3 & 4 & 2 & 50 & 18.5 & $104^{b}$ \\
\hline Mean & 9.9 & & & & & & 46 & 18.0 & $116^{b}$ \\
\hline
\end{tabular}

GARS = Gilliam Autism Rating Scale; GARS subscales: $\mathrm{SB}=$ stereotyped behavior; $\mathrm{Com}=$ communication; $\mathrm{SI}=$ social interaction; Dev $=$ development; TOT $=$ mean autism quotient (scores of $90-110=$ average probability of autism; $111-120=$ above average probability of autism; 121-130 = high probability of autism); CARS = Childhood Autism Rating Scale (scores of 15-29.5 = not autistic; $30-36.5=$ mild to moderate autism; $37-60=$ severe autism); $\mathrm{ND}=$ not done.

${ }^{\mathrm{a}} \mathrm{OAB}=$ overall adaptive behavior composite from Vineland Adaptive Behavior Scale in age equivalents (months of age).

${ }^{b}$ FSIQ $=$ full-scale intelligence quotient (Wechsler Intelligence Scale for Children, thitd edition).

TN). Measured attenuation and decay correction was applied to all images.

The standardized uptake value (SUV) method for semiquantitative analysis of tracer accumulation was used $[8,11]$. Regions of interest (ROIs) were drawn on PET images calibrated to microcuries per cubic centimeter, representing the retention of $\left[{ }^{11} \mathrm{C}\right] \mathrm{AMT}$ from 30 to 50 minutes. Because all subjects received a standardized dose based on their weight $(0.1 \mathrm{mCi} / \mathrm{kg})$, calibrated images directly depict the SUV value. The average SUV for individual structures was determined as a weighted average over all planes showing the structure and were normalized to the size of the larger homotopic region (appearing larger because of higher counts) according to the following equation: $S U V_{\mathrm{s}}=R O I_{\mathrm{s}}(\mu \mathrm{Ci} / \mathrm{cc})$

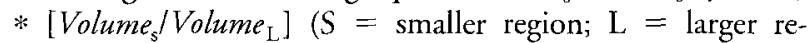
gion). A percent asymmetry score (AS) for each homologous pair was defined as follows: $A S=1\left[S U V_{\mathrm{R}}-S U V_{\mathrm{L}}\right] /\left[\left(S U V_{\mathrm{R}}\right.\right.$ $\left.\left.+S U V_{\mathrm{L}}\right) / 2\right] \mid * 100 \%(\mathrm{R}=$ right; $\mathrm{L}=$ left $)$. Comparison of asymmetry scores obtained from the sibling group with those obtained from the autistic boys was performed using multivariate analysis of variance (MANOVA). $p<0.05$ was considered statistically significant. In addition, statistical comparisons between groups for individual ROIs were performed by using a two-tailed independent-group $t$ test [12].

\section{Results}

All autistic subjects met the criteria of the Diagnostic and Statistical Manual of Mental Disorders, fourth edition (DSM-IV; APA, 1994), for autistic disorder, confirming previous diagnoses by treating psychiatrists or neurologists. The autistic subjects had no other identi- fiable neurological disorders. Results of the Gilliam Autism Rating Scale (GARS) and the Childhood Autism Rating Scale (CARS) for autistic subjects are shown in Table 1. None of the siblings was classified as autistic by the GARS or the CARS. The mean Full Scale IQ for the sibling group was 116 (range, 104-130); reliable IQ measurements could not be obtained for the autistic group. The mean overall adaptive behavior composite age equivalent for the autistic group was 22 months (range, 16-29 months).

Visual examination of PET images of $\left[{ }^{11} \mathrm{C}\right] A M T$ accumulation revealed distinct differences between autistic boys and their siblings (Fig 1). Gross asymmetries of serotonin synthesis in frontal cortex, thalamus, and cerebellum were immediately evident in all 7 boys but not in the 1 autistic girl studied. Decreased [ $\left.{ }^{11} \mathrm{C}\right] \mathrm{AMT}$ accumulation was seen in the left frontal cortex and thalamus in 5 of the 7 boys. This was accompanied by elevated $\left[{ }^{11} \mathrm{C}\right] \mathrm{AMT}$ accumulation on the right dentate nucleus of the cerebellum, confirmed through PET/ magnetic resonance imaging (MRI) image coregistration (Fig 2). It is noteworthy that the dentate nucleus is not visualized with $\left[{ }^{1} \mathrm{C}\right] \mathrm{AMT}$ in normal adults [7, 8]. In the remaining 2 autistic boys, $\left[{ }^{11} \mathrm{C}\right] \mathrm{AMT}$ accumulation was decreased in the right frontal cortex and thalamus and elevated in the left dentate nucleus, a pattern that is the mirror image of that seen in the other autistic boys. It does not appear that this "reversed" pattern of abnormality in these 2 boys is related to 


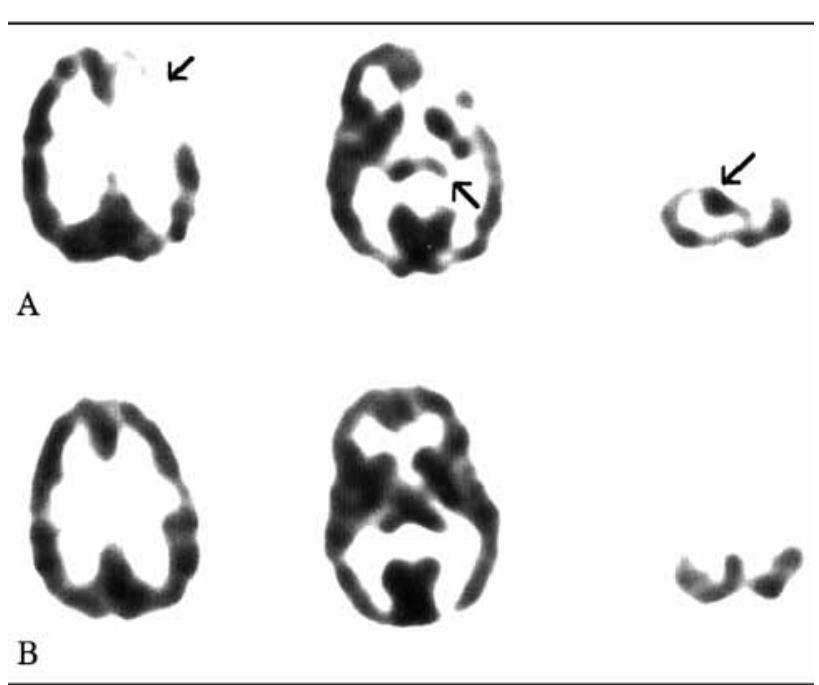

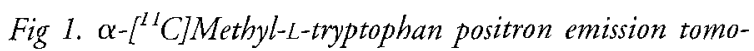
graphic images of a 6.8-year-old autistic boy $(A)$ and a 9.4year-old male sibling $(B)$ (left side of image is the right side of the brain. Arrows denote decreased serotonin synthesis in left frontal cortex and left thalamus and increased serotonin synthesis in right dentate nucleus in the autistic child.

handedness or any other distinct symptomatology. No gross asymmetries were seen in the frontal cortex or thalamus of the sibling group; however, 1 sibling showed increased $\left[{ }^{11} \mathrm{C}\right] \mathrm{AMT}$ accumulation in the right dentate nucleus (see Table 1, Subject 13). It is interesting that this boy had a history of calendar calculation and ritualistically lined up his toys.

The overall difference for asymmetry scores between the autistic boys and siblings was statistically significant (MANOVA, $p<0.05$ ). Differences for regional asymmetry scores (Table 2$)$ in the frontal cortex $(p=$ $0.049)$ and thalamus ( $p=0.016$ ) were also statistically

Fig 2. Coregistration $\left.\alpha-l^{11} C\right]$ methyl-L-tryptophan standardized uptake value positron emission tomographic (PET) images with magnetic resonance imaging (MRI). PET and MRI images were coregistered using the Multi Purpose Imaging Tool [21], and a region of interest was drawn around the right dentate nucleus on the MRI (A) and applied to the PET image (B) by using CTI Sunview software.

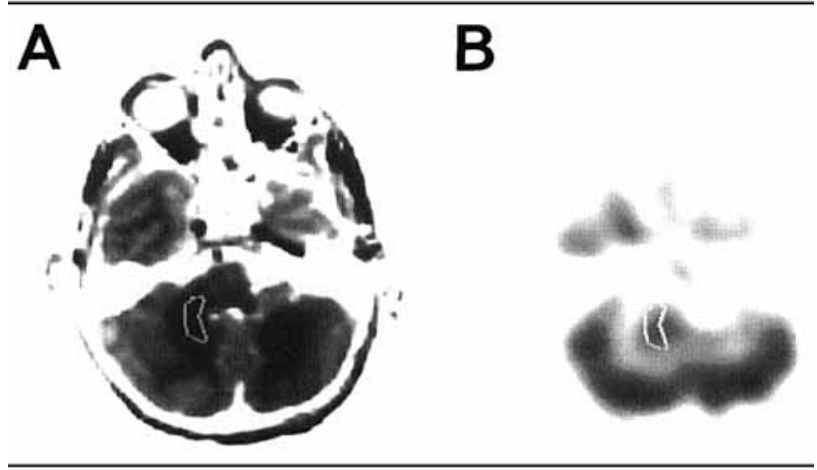

Table 2. Percent Asymmetry Scores for Autistic Boys and Siblings

\begin{tabular}{llll}
\hline ROI & $\begin{array}{l}\text { Autistic Boys } \\
(\mathrm{n}=7)\end{array}$ & $\begin{array}{l}\text { Siblings } \\
(\mathrm{n}=5)\end{array}$ & $p$ \\
\hline Frontal cortex & $27 \pm 18$ & $9 \pm 9$ & 0.049 \\
Thalamus & $25 \pm 13$ & $8 \pm 5$ & 0.016 \\
Dentate nucleus & $13 \pm 8$ & $6 \pm 5$ & 0.076 \\
\hline
\end{tabular}

Data are mean $\pm S D$.

ROI $=$ region of interest.

significant. The asymmetry scores for the dentate nucleus showed a trend toward significance $(p=0.076)$ but did not reach statistical significance due to the presence of increased tracer in this region in 1 of the siblings, as discussed above.

\section{Discussion}

The current study demonstrates neurochemical abnormalities in the brains of autistic boys. All 7 boys showed unilateral decreases of serotonin synthesis in frontal cortex and thalamus associated with increased serotonin synthesis in the contralateral dentate nucleus of the cerebellum. The 1 girl included in the present study showed no cortical, thalamic, or cerebellar asymmetry in her $\left[{ }^{11} \mathrm{C}\right] A M T$ PET scan. This contrast between the boys and the 1 girl studied may be related to gender differences in hemispheric specialization, but this requires further study. Due to ethics constraints in studying normal children of less than the age of assent, we cannot rule out the unlikely possibility that normal boys younger than 8 years old might display asymmetries in serotonin synthesis similar to those seen in the autistic boys.

The three brain regions showing abnormal serotonin synthesis in the present study are synaptically connected via the dentatothalamocortical pathway. Purkinje cells in the cerebellar cortex (which are decreased in number in autistic brain [13]) project to the dentate nucleus, afferents from which constitute the major output pathway of the cerebellum. Dentate neurons project to the ventral lateral nucleus of the contralateral thalamus in the dentatorubrothalamic tract, crossing to the contralateral side of the brain in the decussation of the superior cerebellar peduncle [14-16]. In turn, neurons in the thalamic ventral lateral nucleus project to frontal cortex, including prefrontal cortex, Broca's language area, motor cortex, and supplementary motor cortex [17-20].

The findings of focal abnormalities in serotonin synthesis that are increased in one region and decreased in other brain regions may explain why studies of the serotonin metabolite 5-HIAA in CSF have not demonstrated consistent differences between autistic and control subjects. Focal alterations in $\left[{ }^{1} \mathrm{C}\right] \mathrm{AMT}$ accu- 
mulation may represent either aberrant innervation by serotonergic terminals or altered function in anatomically normal pathways. Immunocytochemical studies in pathological specimens are necessary, to determine which is the case. Altered serotonergic neuromodulation of dentatothalamocortical synaptic activity could be one pathophysiological mechanism underlying dysfunction in autism.

These studies were supported in part by the Mental Illness Research Association (MIRA) of Michigan, to which we are grateful.

We are indebted to Drs Giovanna Spinella and Ralph-Axel Müller for reviewing this manuscript; Dr Joel Ager and Mr James Janisse from the Center for Health Care Effectiveness Research for statistical advice; Dr Donald Kuhn for plasma tryptophan measurements; and to the staff of the PET Center for their assistance in performing these studies.

\section{References}

1. Ciaranello AL, Ciaranello RD. The neurobiology of infantile autism. Annu Rev Neurosci 1995;18:101-128

2. Bailey A, Phillips W, Rutter M. Autism: towards an integration of clinical, genetic, neuropsychological, and neurobiological perspectives. J Child Psychol Psychiatry 1996;37:89-126

3. Schain RJ, Freedman DX. Studies on 5-hydroxyindole metabolism in autism and other mentally retarded children. J Pediatr 1961;59:315-320

4. Anderson GM, Horne WC, Chatterjee D, Cohen DJ. The hyperserotonemia of autism. Ann NY Acad Sci 1990;600:331340

5. Cook EH. Autism: review of neurochemical investigation. Synapse 1990;6:292-308

6. Diksic M, Nagahiro S, Chaly T, et al. Serotonin synthesis rate measured in living dog brain by positron emission tomography. J Neurochem 1991;56:153-162

7. Muzik O, Chugani DC, Chakraborty $P$, et al. Analysis of $\alpha$ $\left[{ }^{11} \mathrm{C}\right]$ methyltryptophan kinetics for the estimation of serotonin synthesis rate in vivo. J Cereb Blood Flow Metab (In press)

8. Chugani DC, Muzik O, Chakraborty $P$, et al. Human brain serotonin synthesis capacity measured in vivo with $\alpha-\left[{ }^{11} \mathrm{C}\right]$ methyl-L-tryptophan. Synapse (In press)

9. Brooks RA, Di Chiro G, Zukerberg BW, et al. Test-retest studies of cerebral glucose metabolism using fluorine-18 deoxyglucose: validation of method. J Nucl Med 1987;28:53-59

10. Chakraborty PK, Manger TJ, Chugani DC, et al. A high-yield and simplified procedure for the synthesis of $\alpha-\left[{ }^{11} \mathrm{C}\right]$ methyl-Ltryptophan. Nucl Med Biol 1996;23:1005-1008

11. Woodard HQ, Gigler RE, Freed B, Russ G. Expression of tissue isotope distribution. J Nucl Med 1975;16:958-959

12. Stevens J. Applied multivariate statistics for the social sciences. 2nd ed. Hillsdale, NJ: Lawrence Erlbaum, 1992:160-161

13. Bauman ML, Kemper TL. Histoanatomic observations of the brain in early infantile autism. Neurology 1985;35:866-875

14. Thach WT, Jones EG. The cerebellar dentatothalamic connection: terminal field, lamellae, rods and somatotopy. Brain Res $1973 ; 169: 168-172$

15. Stanton GB. Topographical organization of ascending cerebellar projections from the dentate and interposed nuclei in Macaca mulatta: an anterograde degeneration study. J Comp Neurol 1980;190:699-731

16. Asanuma C, Thach WT, Jones EG. Distribution of cerebellar terminations and their relation to other afferent terminations in the ventral lateral thalamic region of the monkey. Brain Res Rev 1983;5:267-297

17. Allen GI, Tsukuhara N. Cerebrocerebellar communication systems. Physiol Rev 1974;54:957-1008

18. Middleton FA, Strick PL. Anatomical evidence for cerebellar and basal ganglia involvement in higher cognitive function. Science 1994;266:458-461

19. Orioli P], Strick PL. Cerebellar connections with the motor cortex and the arcuate premotor area: an analysis employing retrograde transneuronal transport of WGA-HRP. J Comp Neurol 1989;288:621-626

20. Schell GR, Strick PL. The origin of thalamic inputs to the arcuate premotor and supplementary motor areas. J Neurosci $1984 ; 4: 539-560$

21. Pietrzyk U, Herholz K, Fink G, et al. An interactive rechnique for three-dimensional image registration: validation for PET, SPECT, MRI and CT brain studies. J Nucl Med 1994;35: 2011--2018 